\title{
EXPERIENTIAL LEARNING FOR COMPLEMENTARY CREDIT: A COURSE TO EARN CREDIT FOR EXTRACURRICULAR INVOLVEMENT
}

\author{
Stephen Mattucci, Kate Whalen, Daniel Picone, Joshua Yachouh, Ahmed Fuad Ali \\ McMaster University \\ mattucs@mcmaster.ca
}

\begin{abstract}
Students often have significant learning experiences outside of the classroom, and in particular through their involvement in extracurricular activities. McMaster University has a strong student culture rooted in this type of involvement, and wanted to recognize this experiential learning. These students are often learning a variety of durable skills such as leadership, teamwork, conflict management, and communication. This paper describes the development of a course for students to earn complementary credit for a variety of diverse roles in extracurricular settings across campus.

The development approach was informed by principles of student ownership and self-directed learning, and implemented by a diverse team including the instructor, staff, and students. Several focus groups conducted with actively involved students provided insight on both the structure and content of the course: workshop-style classes, with active learning modules, and opportunities for students to learn from each other. Critical reflection was the primary assessment to encourage students to derive learning from their extracurricular experiences. Preliminary observations from the first offering of the course are promising, in that students are deriving significant value from the course, and their related extracurricular experiential learning.
\end{abstract}

Keywords: Experiential learning, extracurricular activities, complementary credit, durable skills, curriculum development, student ownership, critical reflection

\section{INTRODUCTION}

According to the Association for Experiential Education [1], “experiential learning occurs when carefully chosen experiences are supported by reflection, critical analysis, and synthesis." Experiential learning has been a recent area of focus of the Federal and Provincial governments as well as of post-secondary institutions [2]. Within their Strategic Mandate Agreement with the Ministry of Advanced Education and Skills Development,
McMaster highlights its commitment to "improving the student experience" with one of the primary strategies focused on "engaging students at all levels in advanced research, providing effective experiential learning opportunities, and connecting these experiences to local, provincial, national and international communities."[3]. Within their agreement, McMaster showcases "[t]he many faces of experiential learning", which include internships, capstone courses, clinical placements, and more.

Throughout their post-secondary education, students often have significant learning experiences outside of the classroom, and in particular through their involvement in co-curricular activities. McMaster University has a strong student culture rooted in this type of involvement, and in an effort to recognize this experiential learning, and prevent students from forfeiting these experiences due to heavy course loads, an approach was developed for students to earn course credit. This was first implemented in the form of a technical elective, for experiences on competitive technical design teams [4], and more recently for complementary elective credit for non-technical contributions to co-curricular clubs and teams. Through these experiences, students are developing a variety of "durable" skills such as leadership, teamwork, conflict management, communication, etc.

It is interesting how many different labels the engineering education community has for this broad category of skills. Non-technical, professional, transferable, soft, durable - it makes it challenging to communicate within the field when the community has as many different words as there are skills these words describe. For this paper, the term 'durable' will be used. Once someone learns to have empathy, or negotiate through a conflict for example, these skills tend to be durable, and retained over a lifetime[5]. Technical skills, while a critical tool for an engineer, tend to be lost over time if they are not being used. Engineering curricula needs to be more proficient at developing the durable skills that engineers will use over their careers and lifetimes. 
This work is informed by methodologies including: action research, and students-as-partners. It is primarily framed through the perspective of the course instructor: a teaching and learning postdoctoral fellow, who coordinates a national engineering education initiative focused on collaboration to tackle similar challenges[6]. Since most of the development stage was a team effort, their perspectives are also integrated throughout this work. Aspects of the instructor's teaching philosophy are embedded throughout the project, including: student ownership of their own learning, self-directed learning skills, and the role of motivation in learning. In addition, and where appropriate, the approach was aligned with the goals of the national initiative: collaboration across institutions (with a lens to learning how collaboration happens across institutions on the ground level), and open sharing of information.

This paper describes the approach for developing a course for students to earn complementary credit for a variety of diverse roles in extracurricular clubs and teams across campus. The motivations for the course are described in section 2, including multiple lenses from both of the local institutional and national contexts, the instructor's interests and teaching philosophy, and logistical constraints. Section 3 outlines the entire course development process including the team that was involved, the methods to identify student values through the collection and synthesis of focus group data, and integration of teaching philosophy. Section 4 outlines the structure of the course (learning objectives, classroom format, assessment criteria, and enrolment requirements), and Section 5 provides initial evaluation, challenges, and considerations. Section 6 outlines overall conclusions from the process.

\section{MOTIVATION FOR COURSE}

\subsection{Local Context}

There was a desire within the Engineering Faculty at McMaster to 'walk the walk' when it comes to the value of experiential education to the student learning experience, and extracurricular activities became a strategic focus. The continual demonstrated investment from the dean's office and increased engagement of the industry sector, allowed for additional staff and facilities dedicated to supporting clubs and teams, strengthened relationships with student clubs, and offering of additional programming (e.g. MacChangers[7]). These served as a catalyst with the existing high levels of student engagement for a pragmatic approach to bridge the gap between academic requirements and extracurricular activities: offer students course credit for valuable experiential learning. This was also seen as a tangible way for McMaster to demonstrate the value placed on experiential learning, and legitimize the skills learned through extracurricular activities.
The idea to offer course programming linked to extracurriculars was not new on campus, and was modeled after social sciences and humanities courses. These faculties were consulted in preliminary discussions for transparency and regarding the framing of the course as a complimentary elective. Impromptu discussions were had at all levels between curriculum committees, student groups, and with stakeholders to determine viability. Extra background work within engineering was enabled through the familiarity of many faculty members with extracurricular contexts (e.g. faculty supervisors of clubs teams). The course went through typical course approval processes before the instructor was recruited to develop and teach the complimentary elective.

\subsection{Alignment with National Context}

One common challenge faced by engineering institutions across the nation, is the meaningful integration of durable skills into the curriculum[8]-[10]. Classes which focus on skills such as communication or leadership are often not valued from the student perspective, as they are not integrated with the 'important' technical skills associated with design, or engineering knowledge, or they are devalued symbolically (i.e. offered late at night, not part of core program). Similarly to durable skills, integrating principles of social responsibility also presents challenges. Topics including Indigenous Perspectives, equity, diversity, inclusion, and impact on society tend to be more qualitative than quantitative, and don't always lend to positivistic learning models affiliated with engineering. Finding ways to have students engage with learning these competencies would be of interest to the national context because it would help create future professional engineers with the social responsibility and awareness to work with diverse teams to tackle complex challenges of the future.

From the instructor's perspective, one of the most critical Canadian Engineering Accreditation Board $(\mathrm{CEAB})$ graduate attributes is lifelong learning [11]. The instructor interprets lifelong learning as synonymous with self-directed learning: the ability of one to continue developing skills and competencies under one's own direction beyond a formal learning structure (i.e. beyond university). Lifelong learning is also becoming a theme of importance in the national and international contexts with the rise in interest in metacognition, mindset, grit, and mindfulness.

\subsection{Instructor Interest}

The instructor, a post-doctoral fellow with agency to pursue individual interests, was given the opportunity to develop a course from scratch. Therefore, elements of his own teaching philosophy and research interests are heavily embedded within the course, including: student 
ownership of learning, self-directed learning, and motivation for learning.

\subsection{Constraints}

Although minimal, some of the pre-determined course logistics included: pass/fail credit structure, three credits (typical single-term course value) spread over the fall and winter terms, and students should be able to enroll and succeed despite a conflict with another course in their timetable.

\section{COURSE DEVELOPMENT}

\subsection{Development Team}

Following curriculum committee approval, the course instructor assembled a diverse course development team to help in the initial design of the course. In the fall of 2018, an application was submitted to recruit two student partners from the Students-as-Partners program run by the campus Teaching and Learning Centre, the MacPherson Institute [12]. The program financially supports students to work in partnership with a faculty/instructor/staff member on a pedagogical or curricular initiative. One student was a $3^{\text {rd }}$ year electrical and biomedical engineering student, the other a $4^{\text {th }}$ year honours integrated science student, both with experience on a number of extracurricular clubs and teams. The integrated sciences student had also taken a relevant experiential learning course (Leadership in Sustainability) through the university's Sustainable Future Program, which implemented critical reflection techniques. The sustainability course instructor and developer was also recruited to join the development team, for her experience with experiential learning, and the development of a critical reflection framework and assessment tool. Finally, the student engagement specialist in the faculty engineering was also recruited for his familiarity with the landscape of extracurricular clubs and teams, understanding of successful club practices, and connections to the students who will be the target audience for the course.

\subsection{Identifying Student Needs and Values}

The team agreed the course should be designed with the needs and values of future students as the primary goal. What will students who are highly engaged beyond the classroom find valuable, and how can it be flexible enough to accommodate a range of student roles, needs, and logistical considerations? The team identified several important themes related to the course design, of which more information was needed from the target population of students, to be collected via a series of focus group events. Most themes were explored through the use of open-ended questions, however there were several aspects targeted for specific information (Table 1). The student partners identified 'learning portfolios' as having a negative association within the student culture based on previous attempts at implementing a campus-wide online software platform, as well as the issue of course fees students may not want to pay for something they are doing already for free.

Students were recruited for focus groups through direct connections with the student engagement specialist, and with a marketing strategy identified by the student partners: focus on free food by a favourite local restaurant (in this case: 'Shawarma Pizza'). The student partners and instructor conducted three focus groups with over 50 total engineering undergraduate students heavily involved in extracurricular programs. Each small-group facilitator took notes from their discussion. The data was then consolidated and qualitatively synthesized resulting in the emergence of several key themes.

Table 1: Themes and example questions to guide focus group sessions

\begin{tabular}{|c|c|}
\hline Theme & Sub-themes and Example Questions \\
\hline 1. Student Profile & $\begin{array}{l}\text { - Pre-assessment activity to identify time and energy students spend on } \\
\text { extracurricular activities } \\
\text { - "What skills are most important to your success in ECs?" }\end{array}$ \\
\hline 2. Course Design & $\begin{array}{l}\text { - } \text { Objective criteria for course: "What is your perception of pass/fail courses?" } \\
\text { - In-class structure: "How would you hope to learn with your peers?" } \\
\text { - } \text { Course deliverables and assessments: "What would be most valuable to you? } \\
\text { How do you feel about 'learning portfolios"?" }\end{array}$ \\
\hline 3. Motivation & $\begin{array}{l}\text { - "What makes you want to take a course?" } \\
\text { - Keep asking 'why?' }\end{array}$ \\
\hline 4. Enrolment Pathways & $\begin{array}{l}\text { - "What would make this course worth the money?" } \\
\text { - "How do we make this a bird course and a passion course?" }\end{array}$ \\
\hline 5. Gaps & - "What challenges in ECs have you felt unequipped to deal with?" \\
\hline Mentorship & - "What questions do you have, with nobody to ask?" \\
\hline
\end{tabular}




\subsection{Focus Group Data}

Students identified several skills as important to their roles including: leadership and management, communication, sponsorship and marketing, budgeting, teamwork, and non-technical skills in general. For class structure, students were heavily in favour of workshopstyle classes, where they have the opportunity to interact with their peers, and learn from classroom guests. For class deliverables and assessments, students preferred tangible outputs that could help them demonstrate the skills they had learned, elements of goal setting and progress tracking, and flexibility (with respect to their extracurricular commitments). In addition, students were open to the idea of critical self-reflection for course assessments.

Students had a negative association with 'learning portfolios' due to an existing bias against a previous online tool some students had experience with, however would be open to the idea if learning portfolios could be flexible, with explicit expectations, and personally relevant output. Some students had issues with some predetermined logistics: pass/fail courses do not allow them to improve their grade point average, and the cost of the course wasn't worth the academic credit for an experience they would already be doing. This issue is exacerbated as Engineering credits have a high per-credit cost relative to many other faculties. The students felt the course should not be perceived as a 'gimme' or 'birdcourse' by the student population. Although an intended goal of the focus groups, it was challenging to gather insight on objective criteria for an adequate level of participation in extracurriculars to qualify for enrollment in the course.

\subsection{Initial Course Outline}

Based on insight gained from the focus groups, the development team designed an initial course outline. The first term would include several workshops, each focused on a specific durable skill, and facilitated by a guest with expertise in that realm. Students would be responsible for attending a subset of the offered workshops. The second term would consist of a flexible project, that would provide value to the students' club or team, and be nontechnical in nature. The course would end with activities focused on articulating outwards the skills they had developed over the year, in both written (e.g. resume or LinkedIn) and verbal forms (e.g. interviews). Course assessments would utilize the Reflection Learning Framework [2], with several opportunities to further develop complex cognitive skills through reflection.

The instructor attended a 3-day course development workshop hosted by the MacPherson Institute 3-months prior to the course deployment. The most beneficial aspects of the workshop were the structure and process framework for approach, devoted work time, course document templates according to university policy (e.g. syllabus), and connections with educational developers at MacPherson for future support and opportunities.

The development approach was informed by principles of student ownership and self-directed learning. Student ownership was highlighted through the involvement of Students-as-Partners throughout the development stage, and heavily emphasized in elements of the course as enrolled students had the flexibility to shape much of their learning experiences in the course. Self-directed learning was emphasized through the implementation of critical reflection as the primary assessment throughout the course. This self-directed learning approach was also intentionally modeled by the instructor by framing course elements as an iterative process for testing and refinement in future course offerings.

\section{COURSE DETAILS}

\subsection{Requirements and Enrolment Process}

Determining the criteria for enrollment was one of the most challenging aspects of course design. The course allows students to earn complementary credit for their non-technical contributions to clubs or teams - which could encompass a very broad range of roles and duties. Therefore two primary requirements were established. First, the student's extracurricular role must be primarily non-technical in nature. This was fairly straightforward as roles that did not include technical engineering duties (e.g. designing the suspension on the Baja car team would not qualify). Second, the level of engagement (i.e. time and energy) the student had with their extracurricular role over the year should be approximately equal to that of a standard 3-credit engineering course.

To verify students met these requirements, an application process was implemented. Students would outline the details of their role(s), and provide a reference. The reference served as a secondary contact to confirm the nature of the student's role, and their level of engagement. Further, it established accountability, as the club or team was now aware the student was earning credit for their contributions.

Enrollment was open until late-September, to allow awareness of the course to spread via word-of-mouth, and give students extra time to commit to extracurriculars for the academic year.

\subsection{Intended Learning Outcomes}

The core idea of the course was for students to earn credit for their experiential learning from their extracurricular roles, therefore the course component was always intended to be minimal, and focused to maximize learning from extracurricular experiences. The courselevel learning outcomes (Table 2) focused on students 
being able to: identify and set goals related to their own skill development, apply self-directed learning techniques, and appropriately articulate durable skills.

Given the lack of familiarity with durable skills, and challenges typically faced with students devaluing the utility of these skills, an additional outcome was focused on the affective learning domain. The affective domain targets feelings, emotions, and attitudes instead the skills typically associated with engineering curricula related to knowledge and mental ability (cognitive domain), or manual and physical skills (psychomotor domain)[13]. Students were not expected to develop mastery of these durable competencies. Instead, the focus was placed on developing students' appreciation for why these competencies are valuable and identifying pathways for potential growth. For example, it would be seen as a success if a student finishes the course recognizing the value of strong communications skills, is aware these skills can be developed and improved with intentional effort, and develops an action plan for doing so. In conjunction with the other learning outcomes around goal-setting and self-directed learning, students would be equipped for the continuous development of their competencies throughout their careers beyond university.

Table 1: Intended Course-Level Learning Outcomes

\begin{tabular}{l} 
By the end of this course, successful students \\
should be able to: \\
\hline 1. Identify specific skills for development related \\
to extracurricular roles and beyond, set \\
relevant and achievable learning outcomes \\
aligned with personal goals, and plan a \\
strategy for learning in a peer-to-peer \\
environment; \\
2. Apply intentional approaches and develop \\
self-awareness towards one's own learning \\
processes, as determined by and through the \\
process of critical reflection and experiential \\
learning; \\
3. Articulate skills developed from experiences \\
in a tangible manner, by conveying through \\
appropriate platforms (e.g. learning portfolio, \\
LinkedIn, resume, interview, etc.); \\
4. Appreciate the complexity, and value the \\
importance of 'durable skills', and be aware of \\
potential development opportunities.
\end{tabular}

\subsection{Course Structure}

The classroom component of the course was structured as workshop-style, where each class contained a variety of active learning activities, where students could work with, and learn from each other (Table 3). The course began with an introduction class, followed by three offerings of a mandatory Reflection Workshop, which introduced students to the RLF as a central learning and assessment tool for the course. Guests were recruited to help facilitate sessions according to their expertise. Students were required to attend at least four "skills workshops" of the seven offered.

Two other workshops were offered (or intended to be offered) at the end of the second term, and were designed to help students learn to articulate the durable skills they had been developing. The first workshop introduced the STAR framework [14] to help students structure their skills in writing. The second workshop was cancelled due to the COVID-19 pandemic, however would have involved mini-mock-interviews (using LinkedIn profiles), with recently graduated engineering alumni. The goal was to provide relevant mentorship opportunities from peers who were only one stage further in their careers, who shared similar extracurricular experiences during undergrad.

\subsection{Course Assessment}

Course assessment was primarily through critical reflection, using a framework developed by one of the team members. Despite the final course outcome determined as pass / fail, all assessments were numerical. In order to best develop critical self-reflection skills, students require targeted feedback to learn what they are doing well and where and how they can improve. The RLF was developed as a tool to guide, assess, and evaluate written reflections by focusing on cognitive and metacognitive skills demonstrated [2]. One of the reasons why the RLF was selected for use in this course was that it helped to remove much of the subjectivity inherent in assessing personal reflections. Furthermore the RLF includes a transparent structure and rubric that supports training, skill development, and feedback.

One full refection assignment (i.e. all eight criteria required) was due after the Reflection Workshop, where students reflected on their previous extracurricular (or coop) experiences, in order to provide some rationale for goal setting for the year. These learning goals would provide a benchmark for the rest of the term for future reflections. Mini-reflection assignments were due following four 'skills workshops' (student choice), where students reflected on three (of the eight total) RLF criteria. A final full reflection assignment concluded the course, where students reflected on their learning throughout the year and how they met their goals.

The second term also included a 'Choose-your-ownadventure'-style project, where students proposed their own idea for a project that would contribute value to their extracurricular club or team while relating to durable skills and the student's learning goals. Students would agree upon a method for measuring success during a project proposal meeting with the Instructor or TA. 
Table 3: Specific workshops offered during first term.

\begin{tabular}{|l|l|l|}
\hline Term 1 & Theme / Competency & Guest Facilitator \\
\hline Introduction Class & $\begin{array}{l}\text { Introductions, syllabus overview, group } \\
\text { expectations, assessments }\end{array}$ & (Course instructor only) \\
\hline $\begin{array}{l}\text { Workshop \#0 } \\
\text { (mandatory) }\end{array}$ & Reflection Learning Framework & (Course instructor only) \\
\hline Workshop \#1 & Sponsorship and Marketing & $\begin{array}{l}\text { Student engagement specialist and } \\
\text { advancement officer }\end{array}$ \\
\hline Workshop \#2 & $\begin{array}{l}\text { Teamwork and Conflict Management \#1 } \\
\text { Conflict 101 }\end{array}$ & $\begin{array}{l}\text { Law mediation arbitrator and } \\
\text { professional engineer }\end{array}$ \\
\hline Workshop \#3 & Leadership and Management & $\begin{array}{l}\text { Director of Leadership Development } \\
\text { Centre at U of Toronto }\end{array}$ \\
\hline Workshop \#4 & Communication & $\begin{array}{l}\text { Co-creator of Transdisciplinary } \\
\text { Classroom at U of Guelph }\end{array}$ \\
\hline Workshop \#5 & Metacognition, Mindset, and Grit & (Course instructor only) \\
\hline Workshop \#6 & $\begin{array}{l}\text { Teamwork and Conflict Management \#2 } \\
\text { Conflict Role-Playing Game }\end{array}$ & $\begin{array}{l}\text { Law mediation arbitrator and } \\
\text { professional engineer }\end{array}$ \\
\hline Workshop \#7 & $\begin{array}{l}\text { Impact on Society and Technological } \\
\text { Stewardship }\end{array}$ & Not-for-profit social change lab [15] \\
\hline
\end{tabular}

\subsection{Logistics}

Classes were scheduled via online poll according to student availability. Where possible the instructor offered multiple sessions for workshops, including for mandatory sessions (i.e. Reflection workshop) to accommodate student schedules. An initial goal was to ensure the course was accessible to students regardless of their extracurricular roles and duties.

One undergraduate TA was hired to support the course. Since this was the first year being offered, the TA's duties were varied to experiment with how best to utilize extra support. This included attending workshops, marking reflection assignments, and managing chooseyour-own-adventure projects. In the future, TAs will likely be recruited from students who have completed the course.

\section{LIMITATIONS AND AREAS FOR IMPROVEMENT}

The first implementation of any course always provides ample opportunities for improvement, and this course is no different. Several challenges were faced along the way, which in itself was not surprising. To model self-directed learning, the instructor was always very transparent about the development of the course, to encourage student feedback to contribute to the continual improvement of the course, but also in improving any approach, skill, or attitude.

One of the expected challenges was determining what extracurricular experiences qualify for course enrolment. The development team tried to develop a criteria that was as objective as possible, but no matter how 'black and white' the initial criteria, grey instances will always be present. For example, we tried to restrict to official McMaster sanctioned clubs, but what about the student who spends $20+$ hours each week mentoring a local highschool robotics team, or the student who is taking an entrepreneurial approach to build a new club? Further, verification of roles can be a challenge, especially when most clubs lack any academic supervision. What about athletics? The team captain of a varsity team likely spends significant time developing leadership, communication, and teamwork skills. As the course evolves, the enrolment criteria will need to be iterated to best adapt to the target student population.

Scheduling a common weekly 'class time' for students across all engineering programs and years of study was a significant challenge. By attempting to accommodate students who had other commitments (either extracurricular or timetable conflicts), the fluidity of scheduling class time required significant administrative time and energy. Additionally, this added the additional challenge of trying to accommodate schedules of anticipated workshop guests.

Multiple opportunities for students to write critical reflections, and receive constructive feedback resulted in a significant improvement in reflection quality. Reflections became less rigid to the rubric structure, including going to greater depth, and exceeding assignment requirements. The instructor and TA both agreed that it appeared students were finding greater value in the process of reflection (student perception to be evaluated after the conclusion of the course).

Many students' initial perceptions of durable skills exhibited 'fixed mindset' tendencies [16]. For example, students felt that people either are or are not 'leaders', or 
that these skills are developed solely through 'experience'. This also emphasized the utility of the learning outcomes in the affective domain.

\section{CONCLUSIONS}

This paper describes the approach for developing a course for students to earn complementary credit for the experiential learning that occurs through extracurricular involvement. The initiation of the course stemmed from a strategic focus on experiential learning, which resulted in several aligned supports and initiatives. The course was designed to fit both the local and national contexts to focus on the development of durable skills, and was framed around student ownership, and self-directed learning. It was developed by a diverse team, including two Students-as-Partners, and the student perspective was identified as a critical component in order to address the development of durable skills in a meaningful way. Student focus groups provided considerable insight towards the structure of the course. Initial observations from the first offering of the course have proved to be promising, in that students are deriving significant value from the course, and their related extracurricular experiential learning.

\section{Acknowledgements}

The authors wish to acknowledge the support of their McMaster colleagues during the course development process, including: Louise Gazzola (Experiential Program Coordinator), Dr. Ken Coley (former Associate Dean Academic).

\section{References}

[1] Association for Experiential Education, "What is Experiential Education?" [Online]. Available: https://www.aee.org/what-is-ee. [Accessed: 16-Feb2020].

[2] K. Whalen and A. Paez, "Development of a New Framework to Guide, Assess, and Evaluate Student Reflections in a University Sustainability Course," Teach. Learn. Inq., vol. 7, no. 1, pp. 55-77, 2019.

[3] Ministry of Advanced Education and SkillsDevelopment, “2017-20 Strategic Mandate
Agreement: McMaster University." [Online]. Available: https://www.ontario.ca/page/2017-20strategic-mandate-agreement-mcmaster-university.

[4] E. Hassan, "New Technical Elective Recognizing Experiential Learning in Competitive Engineering Teams: Lessons from the Inaugural Term of the Course," in Canadian Engineering Education Association (CEEA-ACEG), 2018, pp. 1-6.

[5] I. Puri, "Let's solve wicked problems," Fireside with the Dean (Blog), 2016. [Online]. Available: https://firesidewiththedean.wordpress.com/2016/03/07/1 ets-solve-wicked-problems/.

[6] S. Mattucci, "A Snapshot of the Canadian Engineering Education System: Reflections from an Emerging Scholar Trying to Support National Curriculum Change," in Proceedings of the Canadian Engineering Education Association, 2019, pp. 1-8.

[7] Faculty of Engineering, "MacChangers." [Online]. Available: https://www.eng.mcmaster.ca/co-opcareer/macchangers.

[8] Royal Bank of Canada, "Humans Wanted - How Canadian youth can thrive in the age of disruption," 2018.

[9] J. O. Grady, "2007 Engineering and Technology Employer Survey."

[10] A. T. Kirkpatrick, S. Danielson, and T. Perry, "ASME Vision 2030 -- Recommendations for Mechanical Engineering Education," in ASEE Annual Conference and Exposition, Conference Proceedings, 2012, p. 9.

[11] Engineers Canada, "Canadian Engineering Accreditation Board - 2019 Accreditation Criteria and Procedures," 2019.

[12] E. Marquis et al., "Connecting students and staff for teaching and learning enquiry:," in Developing the Higher Education Curriculum: Research-based Education in Practice, B. Carnell and D. Fung, Eds. 2017, pp. 203-216.

[13] L. W. Anderson et al., A Taxonomy for Learning, Teaching, and Assessing: A Revision of Bloom's Taxonomy of Educational Objectives. Longman, 2001.

[14] J. Tomasson Goodwin, J. Goh, S. Verkoeyen, and K. Lithgow, "Can students be taught to articulate employability skills?," Educ. Train., vol. 61, no. 4, pp. 445-460, 2019.

[15] "Engineering Change Lab." [Online]. Available: https://engineeringchangelab.ca.

[16] C. Dweck, Mindset: The New Psychology of Success. Ballantine, 2007. 